\title{
Induced Systemic Resistance against Botrytis cinerea by Bacillus cereus AR156 through a JA/ET- and NPR1-Dependent Signaling Pathway and Activates PAMP-Triggered Immunity in Arabidopsis
}

\author{
Pingping Nie ${ }^{1,2}$, Xia $\mathrm{Li}^{1,2}$, Shune Wang ${ }^{1,2}$, Jianhua Guo ${ }^{1,2}$, Hongwei Zhao ${ }^{1,2 *}$ and \\ Dongdong Niu ${ }^{1,2 *}$
}

${ }^{1}$ Department of Plant Pathology, College of Plant Protection, Nanjing Agricultural University, Nanjing, China, ${ }^{2}$ Key Laboratory of Integrated Management of Crop Diseases and Pests, Nanjing Agricultural University, Ministry of Education, Nanjing, China

OPEN ACCESS

Edited by: Gero Benckiser, University of Giessen, Germany

Reviewed by: Akanksha Singh, Central Institute of Medicinal and Aromatic Plants, India Prashant Singh, Lancaster University, UK

${ }^{*}$ Correspondence: Dongdong Niu

ddniu@njau.edu.cn Hongwei Zhao

hzhao@njau.edu.cn

Specialty section: This article was submitted to Plant Microbe Interactions, a section of the journal Frontiers in Plant Science

Received: 09 December 2016 Accepted: 08 February 2017 Published: 28 February 2017

Citation:

Nie P, Li X, Wang S, Guo J, Zhao H and Niu D (2017) Induced Systemic Resistance against Botrytis cinerea by

Bacillus cereus AR156 through a JAJET- and NPR1-Dependent

Signaling Pathway and Activates PAMP-Triggered Immunity in Arabidopsis. Front. Plant Sci. 8:238. doi: $10.3389 / \mathrm{fp} / \mathrm{s} .2017 .00238$
Induced resistance response is a potent and cost effective plant defense against pathogen attack. The effectiveness and underlying mechanisms of the suppressive ability by Bacillus cereus AR156 to Pseudomonas syringae pv. tomato DC3000 (Pst DC3000) in Arabidopsis has been investigated previously; however, the strength of induced systemic resistance (ISR) activity against Botrytis cinerea remains unknown. Here, we show that root-drench application of AR156 significantly reduces disease incidence through activation of ISR. This protection is accompanied with multilayered ISR defense response activated via enhanced accumulation of PR1 protein expression in a timely manner, hydrogen peroxide accumulation and callose deposition, which is significantly more intense in plants with both AR156 pretreatment and B. cinerea inoculation than that in plants with pathogen inoculation only. Moreover, AR156 can trigger ISR in sid2-2 and NahG mutants, but not in jar1, ein2 and npr1 mutant plants. Our results indicate that AR156-induced ISR depends on JA/ET-signaling pathway and NPR1, but not SA. Also, AR156-treated plants are able to rapidly activate MAPK signaling and FRK1/WRKY53 gene expression, both of which are involved in pathogen associated molecular pattern (PAMP)-triggered immunity (PTI). The results indicate that AR156 can induce ISR by the JA/ET-signaling pathways in an NPR1-dependent manner and involves multiple PTI components.

Keywords: Bacillus cereus AR156, induced systemic resistance, salicylic acid (SA), jasmonic acid (JA), ethylene (ET)

\section{INTRODUCTION}

Plants are protected from pathogen attack through activation of innate immune system, which is a consequence of co-evolution between plants and their pathogens (Jones and Dangl, 2006). The emergence of pathogens is first detected by pattern recognition receptors (PRRs) that are localized on plant cell membrane. PRRs percept the conserved pathogen identification 
molecules known as pathogen-associated molecular patterns (PAMPs), which include flagellin, lipopolysaccharides, glycoproteins, or chitin (Jones and Dangl, 2006). The interaction between PRRs and PAMPs consequently triggers the socalled PAMP-triggered immunity (PTI), which initiates many immune responses, including oxidative burst, callose deposition, activation of the MAPK (mitogen-activated protein kinase) cascade, and defense-related gene expression (Altenbach and Robatzek, 2007; Schwessinger and Zipfel, 2008). During the course of evolution, some successful pathogens emerged that can successfully infect plants by suppressing PTI. This suppression is achieved by secreting virulent proteins generically termed effectors, which causes effector-triggered susceptibility (ETS) consequently (Speth et al., 2007). In response to effectors, some plants have evolved resistance $(\mathrm{R})$ proteins, which can recognize effectors directly or indirectly, and elicit effectortriggered immunity (ETI). ETI usually is accompanied with a hypersensitive response (HR) at the infection site, which is thought to restrict biotrophic pathogen growth (Chisholm et al., 2006; Jones and Dangl, 2006).

Beyond defense response against an intermediate infection, resistance can be induced by a temporarily prior infection that is effective for a certain period of time, and to a broad spectrum of pathogens temporarily after (Fu and Dong, 2013). The induced defense responses can be activated by pathogen infection, microbial symbiosis, or other elicitation, such as wounding. There are two types of induced resistances that are phenotypically hard-to-distinguished: the induced systemic resistance (ISR) and systemic acquired resistance (SAR). ISR is a systemic resistance induced by some non-pathogenic rhizobacteria that can suppress disease in plants (van Loon et al., 1998). In contrast, SAR is an induced resistance that develops in whole plants in response to a temporally earlier local exposure to a pathogen. In both SAR and ISR, phytohormone signaling pathways, such as salicylic acid (SA), jasmonic acid (JA), and ethylene (ET) are found to play crucial regulatory roles (Glazebrook, 2001).

Induced systemic resistance (ISR) has been reported in many plant species, such as rice, bean, carnation, cucumber, radish, tobacco, tomato, and Arabidopsis, which is effective against a broad spectrum of plant pathogens, ranging from fungi, bacteria, to viruses, and even to insect herbivores (Van der Ent et al., 2008; Pieterse et al., 2014). ISR requires JA and ET signaling pathways and is associated with the expression of the gene encoding plant defensin 1.2 (PDF1.2) (Van Oosten et al., 2008). For example, the rhizobacterial strain Pseudomonas fluorescens WCS417 $r$ has been shown to trigger ISR in several plant species and in Arabidopsis, where it functions through JA/ET signaling pathways and in a NPR1-dependent manner (Pieterse et al., 2002). However, dependence on both SA- and JA/ET-signaling pathways is also observed. For example, we previously reported that the ISR mediated by the rhizobacterium Bacillus cereus strain AR156 requires both the SA and JA/ET signaling pathways and NPR1 (Niu et al., 2011). Also, colonization of Arabidopsis roots by Trichoderma atroviride IMI 206040 induces the expression of SA and JA/ET pathways simultaneously to confer resistance against hemibiotrophic and necrotrophic phytopathogens (Salas-Marina et al., 2011).
In most cases, ISR is associated with a potentiated defensive capacity, which is termed "priming". Priming does not cause a direct induction of resistance-related genes, or enhance the production of phytohormones or hormone-responsive genes in systemic tissues. Instead, ISR enhances the sensitivity to hormones rather than their synthesis. Therefore, priming is costeffective in increasing plant resistance and is more efficient in activating defense mechanisms upon pathogen attack (Conrath et al., 2006; Pastor et al., 2013). Beneficial rhizobacteria trigger ISR by priming the plant for potentiated activation of varieties of cellular defense responses, such as oxidative burst (Ahn et al., 2007), cell-wall reinforcement (Heil and Bostock, 2002), defense-related enzymes accumulation (Rahman et al., 2014), and secondary metabolites production (Yedidia et al., 2003).

In our previous study, the beneficial bacterium $B$. cereus AR156 was demonstrated to trigger ISR in Arabidopsis through both the SA- and JA/ET- signaling pathways, which lead to enhanced resistance to bacterial infection (Niu et al., 2011). As an effort to further dissect the mechanism of AR156-mediated ISR, we are prompted to explore more protective potential of this bacterium. Botrytis cinerea, a necrotrophic fungus causing gray mold disease, is considered an important pathogen around the world. In this study, we show that $B$. cereus AR156 treatment inhibits B. cinerea infection in Arabidopsis through activation of ISR. The potency of induced protection is lost in jar1, ein2 and npr1 mutant but unaffected in sid2-2 and NahG plants, implicating the JA/ET signaling pathway and NPR1 are required but the SA signaling pathway is dispensable for AR156-induced ISR to $B$. cinerea infection. We also show that the primed defense in AR156-treated plants is mediated by enhanced activation of multiple PTI defense responses.

\section{MATERIALS AND METHODS \\ Plants and Growth Conditions}

Arabidopsis thaliana plants were maintained at $22^{\circ} \mathrm{C}$ with a $12-\mathrm{h}$ light/12-h dark photoperiod. Arabidopsis thaliana ecotype Col0 and mutants were cultivated in vermiculite. All plants were used for experiments when they were 4 weeks old. The mutants used in this study (sid2-2, NahG, jarl, ein2, npr 1) were described elsewhere (Staswick et al., 1992; Bowling et al., 1994; Delaney, 1994; Alonso et al., 1999).

\section{AR156 Treatment, Pathogen Inoculation, and Disease Assays}

Bacillus cereus AR156 was grown on Luria-Bertani (LB) agar plates at $28^{\circ} \mathrm{C}$ for $24 \mathrm{~h}$. Subsequently, bacterial cells were pelleted by centrifugation and were resuspended in sterile $0.85 \%$ $\mathrm{NaCl}$ with a final concentration of $5 \times 10^{8} \mathrm{CFU} / \mathrm{ml}$. For a protection assay, AR156 or corresponding mock $(0.85 \% \mathrm{NaCl})$ was root-drench applied 7 days prior infection. For fungal infection experiments, 4-weeks-old plants were used. Botrytis cinerea strain B1301 was cultivated on PSA agar medium for 7 days. Spores were collected in $B$. cinerea infection buffer to prepare the inoculum and adjusted to a final concentration of $1 \times 10^{6}$ spores $/ \mathrm{ml}$. Inoculation was carried out by depositing a $10 \mathrm{ul}$ droplet on each side of the midvein. Ten inoculated 
plants for each genotype were placed in plant growth room maintained at a high humidity. For each time point, at least three biological replicates were analyzed. In planta fungal growth was examined by analyzing the transcript levels of $B$. cinerea actin gene (BcActin) using primer BcActin-1F (5'-TCC AAG CGT GGT ATT CTT ACC C-3') and BcActin-1R (5' - TGG TGC TAC ACG AAG TTC GTT G-3'). The Arabidopsis actin gene (AtActin2) amplified by primer AtActin2-1F (5'-GGC GAT GAA GCT CAA TCC AAA CG-3') and AtActin2-1R (5'-GGT CAC GAC CAG CAA GAT CAA GAC G-3') was used as an internal control.

\section{RNA Extraction and qRT-PCR Analysis of Gene Expression}

Total RNA was extracted from Arabidopsis leaves with TRIzol Reagent (Invitrogen, San Diego, CA, U.S.A). In brief, 1 ug total RNA was used for cDNA synthesis by using a commercial reverse transcription system (TaKaRa Biotech, Dalian, China). After the cDNA was diluted 10 times, 2 ul diluted cDNA was used for realtime quantitative PCR with the following program: 40 cycles at $95^{\circ} \mathrm{C}$ for $30 \mathrm{~s}, 55^{\circ} \mathrm{C}$ for $30 \mathrm{~s}$, and $72^{\circ} \mathrm{C}$ for $34 \mathrm{~s}$. Three replications were performed for each sample. The data were normalized with AtActin, and the means of three replications were presented. Primers used in qRT-PCR were listed in Table S1.

\section{Examination of Hydrogen Peroxide Accumulation and Callose Deposition}

Hydrogen peroxide accumulation and callose deposition examination was performed according to previously described procedures (Niu et al., 2011). Briefly, for accumulation of ROS, Arabidopsis leaves from at least three different plants were stained with $\mathrm{DAB}$ solution ( $1 \mathrm{mg}$ of diaminobenzidine per milliliter, $\mathrm{pH} 3.8$ ) for $8 \mathrm{~h}$ dark at 25 to $28^{\circ} \mathrm{C}$. After being cleared with $96 \%$ ( $\mathrm{vol} / \mathrm{vol}$ ) ethanol and preserved in 50\% (vol/vol) ethanol, hydrogen peroxide was visualized as dark-brown precipitate under the light microscope. For callose deposition, Arabidopsis leaves were immerged in $5 \mathrm{ml}$ of destaining solution (Acetic acid/ethanol $=5: 95)(\mathrm{vol} / \mathrm{vol})$ and were infiltrated by applying a vacuum for 5 to $10 \mathrm{~min}$. Leaves were incubated in a $60^{\circ} \mathrm{C}$ water bath for 20 to $30 \mathrm{~min}$ to clear chlorophyll. The chlorophyll-free leaves were gently rinsed with water and were then soaked in 3 to $5 \mathrm{ml}$ of $0.01 \%$ (wt/vol) aniline blue staining solution containing $150 \mathrm{mM} \mathrm{K} \mathrm{HPO}_{4}$ (pH 9.5) kept in dark for 2 to $4 \mathrm{~h}$. After staining, Arabidopsis leaves were gently rinsed with water and were then mounted on microscope slides that were observed under an epifluorescence microscope with a UV excitation filter. Levels of callose deposition were quantified using Imge J software and expressed relative to total leaf area as described (Luna et al., 2011).

\section{Protein Extraction and Analysis}

Plant tissue was ground in liquid nitrogen and total proteins were extracted using $2 \times$ SDS loading buffer. The samples were resolved on SDS-PAGE gels and transferred onto nitrocellulose membranes. The blots were probed with appropriate antibodies: monoclonal mouse anti- $\alpha$ tubulin (1:4,000 dilution); polyclonal rabbit anti-PR1 (1:2,000 dilution). For MAPK activity assay, sample were analyzed by Western blotting using monoclonal rabbit phospho-p44/42 MAPK (Erk1/2) (Thr202/Tyr204) (D13.14.4E) XP antibodies (Cell Signaling Technology, \#4370S, $1: 2,000$ dilution). For these assays, $\alpha$-tubulin was used as a loading control.

\section{RESULTS}

\section{B. cereus AR156 Induces an Effective ISR against Botrytis cinerea Infection}

We previously found in Arabidopsis that B. cereus AR156 could prime the whole plant for an induced resistance to Pst DC3000 infection. In this study, we designed experiments to test whether AR156 is able to induce ISR against $B$. cinerea as well. Arabidopsis was first pretreated with AR156 or mock $(0.85 \% \mathrm{NaCl})$ for 7 days in a root-drench application manner, followed by $B$. cinerea infection. Effect of AR156 on ISR was examined by the plant performance against pathogen infection. Two days after pathogen inoculation, mock-treated plants showed typical symptoms of $B$. cinerea disease-severe necrosis around inoculating loci, leaves yellowing, and watersoaked spots surrounded by the spores (Figure 1A). In contrast, plants with AR156-pretreatment exhibited a significant $(P<$ 0.01 ) reduction on disease symptoms, manifested by smaller necrosis size, less yellowing, compared with mock-treated plants (Figure 1B). As an indicator of the effectiveness of elimination of pathogen infection, fungal hyphae were measured 2 days after inoculation (dpi) by qRT-PCR. In agreement with the reduced disease symptom observed on leaf surface, significantly reduced fungal hyphae were detected inside leaf tissue from AR156pretreated plants than that with control pre-treatment, indicating AR156 effectively protected Arabidopsis from B. cinerea infection (Figure 1C).

\section{AR156 Induces ISR by Potentiating PR1 Expression, Hydrogen Peroxide Accumulation, and Callose Deposition in Arabidopsis}

Establishment of ISR is usually accompanied with potentiated activation of various cellular defense responses against pathogen infection, which was called priming (Conrath et al., 2001). To investigate whether AR156-induced ISR was accompanied with primed defense responses in systemic leaves, we measured the expression level of defense-related protein PR1. With AR156 or control pre-treatment alone, PR1 expression was almost negligible prior pathogen infection, indicating AR156 by itself in not capable of inducing PR1 expression (Figure 2A). At 12 hpi, elevated PR1 expression was detected in B. cinerea-infected leaves, indicating the Arabidopsis innate immunity system recognizes and responds rapidly against $B$. cinerea infection. Moreover, plants with AR156 pre-treatment accumulated much higher PR1 than the control treated plants did. These results indicate that in plants with AR156 pretreatment, the innate immunity system is at a potentiated status so that plants could launch a much accelerated defense response upon infection (Figure 2A). 
A
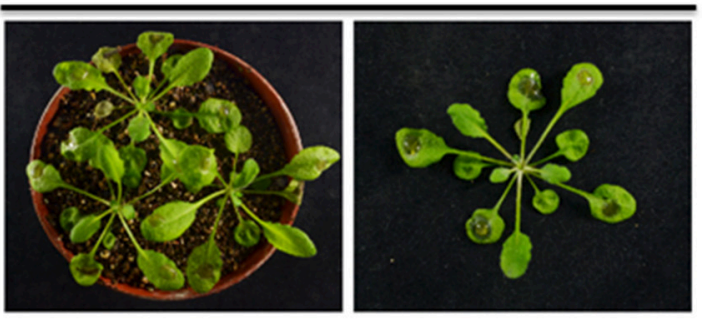

B

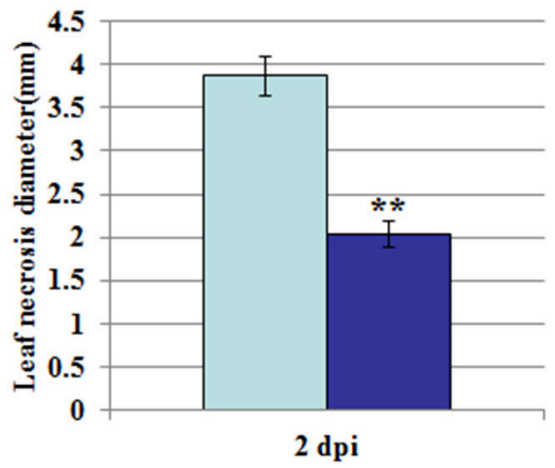

AR156/B.cinerea

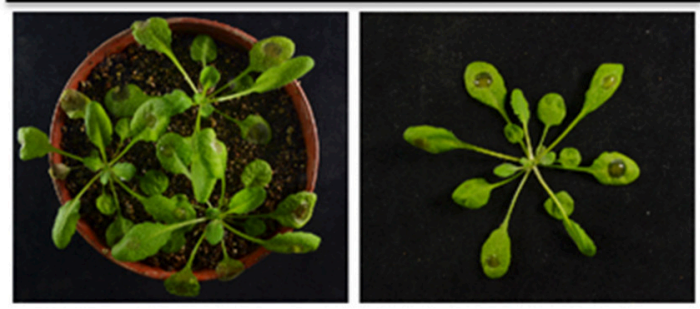

C
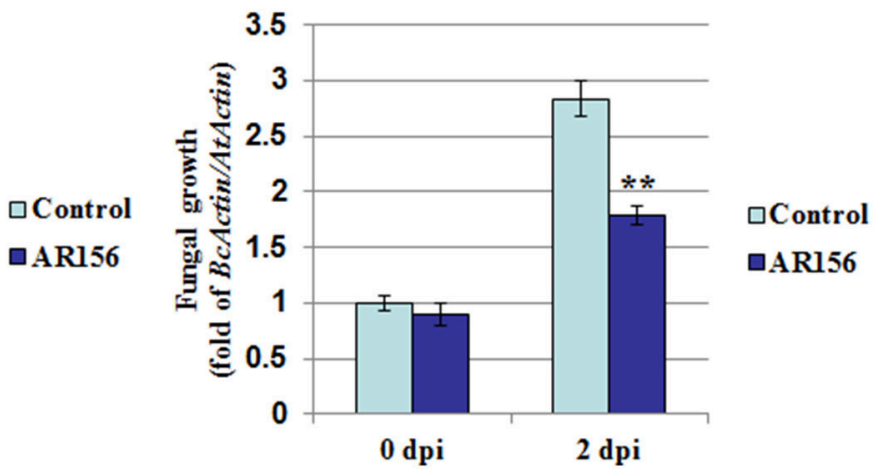

FIGURE 1 | B. cereus AR156 induces an effective ISR against B. cinerea infection. Arabidopsis Col-0 plants are drench-applied with AR156 at $5 \times 10^{8}$ $\mathrm{CFU} / \mathrm{ml}$ or $0.85 \% \mathrm{NaCl}$ (Control). Control-or AR156-treated plants (7 days) are inoculated by depositing a $10 \mathrm{ul}$ droplet of $B$. cinerea spores (1 $\times 10^{6}$ spores/ml) on each side of the midvein. (A) Disease symptoms observation and photo talking were made 2 days post infection (dpi). (B) Leaf necrosis development was evaluated at 2 dpi by measuring the average necrosis diameter on five leaves per plants for 10 plants (Col-0). (C) In planta growth of $B$. cinerea. Measurement of fungal growth was carried out by simultaneous quantification of the expression levels of B. cinerea Actin gene (BcActin) and the Arabidopsis Actin gene (AtActin). Relative fungal growth was determined by ratios of BcActin/AtActin. A Student's $t$-test was used to determine significant differences between the AR156-treated sample and the control ${ }^{\star \star} P$ $<0.01)$. The means values $\pm S D(n=12)$ from one representative experiment among three independent repeats are shown.

To investigate the molecular mechanism of AR156-mediated ISR, $\mathrm{H}_{2} \mathrm{O}_{2}$ accumulation and callose deposition pattern were examined in plants inoculated with $B$. cinerea, with or without AR156 pretreatment. $\mathrm{H}_{2} \mathrm{O}_{2}$ accumulation and callose deposition are two rapid responses elicited by pathogen infection, intensity and rapidity of which are hallmarks of successful immune response. AR156 neither induce the production of $\mathrm{H}_{2} \mathrm{O}_{2}$ at 12 hpi, nor $24 \mathrm{hpi}$, indicating that AR156 itself is not an elicitor of plant defense (Figure 2B). At $12 \mathrm{hpi}, \mathrm{B}$. cinerea infection alone did not induce measurable $\mathrm{H}_{2} \mathrm{O}_{2}$ accumulation, indicating at this stage of infection, plants were not able to deploy an effective defense response yet, in term of $\mathrm{H}_{2} \mathrm{O}_{2}$ accumulation. However, in plants pretreated with AR156, detectable $\mathrm{H}_{2} \mathrm{O}_{2}$ level was observed, indicating AR156 pretreatment potentiated plants for an expiated immune response (Figure 2B). At $24 \mathrm{hpi}$, detectable $\mathrm{H}_{2} \mathrm{O}_{2}$ level was observed in plants inoculated with B. cinerea, indicating an initiation of $\mathrm{H}_{2} \mathrm{O}_{2}$-mediated defense response later than $12 \mathrm{hpi}$ but before $24 \mathrm{hpi}$. In accordance with observation made at $12 \mathrm{hpi}, \mathrm{AR} 156$ pretreatment increased the extent of $\mathrm{H}_{2} \mathrm{O}_{2}$ accumulation upon $B$. cinerea infection (Figure 2B). We also compared callose deposition between plants with and without AR156 pretreatment (Figures 2C,D). Similar to $\mathrm{H}_{2} \mathrm{O}_{2}$ accumulation, AR156 alone did not induced any detectable callose deposition. With $B$. cinerea infection, at $12 \mathrm{hpi}$, callose deposition was detectable, indicating plants were able to perceive the pathogen infection and response efficiently. Moreover, in plants pretreated with AR156, callose deposition was noticeably enhanced, indicating a potentiated defense response due to AR156 pretreatment. In agreement, callose deposition at $24 \mathrm{hpi}$ exhibited similar pattern. Taken together, our results indicate that AR156 primes plants for accelerated and enhanced immune capacity, which is induced only upon pathogen attack and leads to rapidly activated cellular defense responses in systemic tissue.

\section{AR156-Mediated ISR Is Dependent of the JA/ET Signaling Pathway and NPR1}

To further elucidate the molecular mechanisms responsible for AR156-triggered ISR, plants defective in different hormone signaling pathways were analyzed. As indicated in Figure 3A, 2 days after pathogen infection, $B$. cinerea caused visible disease symptom on both wild type (Col-0) and sid2-2, NahG, jar1, ein2, npr1 mutant plants, indicating none of the mutant plants exhibited an automatic and effective immune response against B. cinerea infection (Figure 3A, control set). Pretreatment with AR156 led to a reduction in disease symptom on Col-0, sid22 and NahG plants, indicting protection mediated by AR156 is still functional in these mutants as effective as in corresponding 


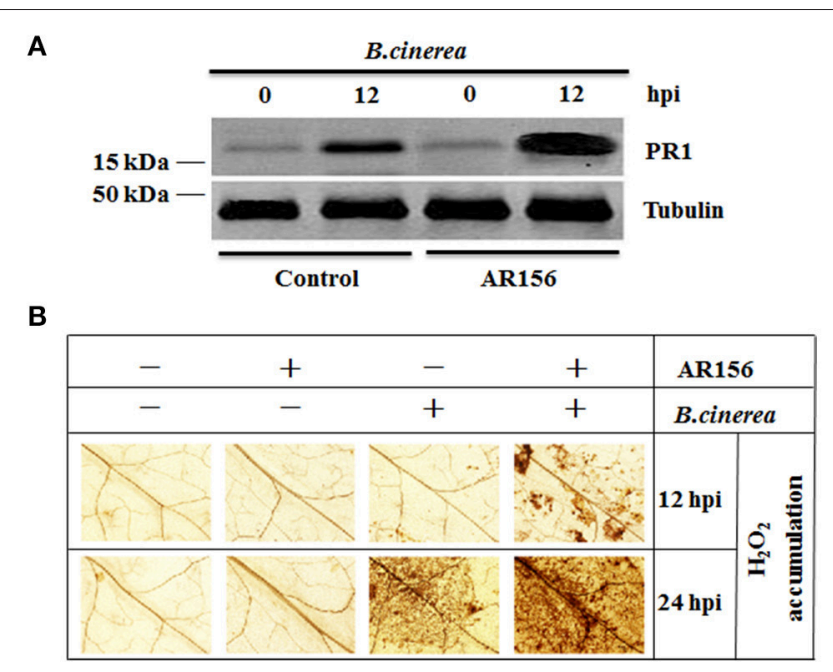

C

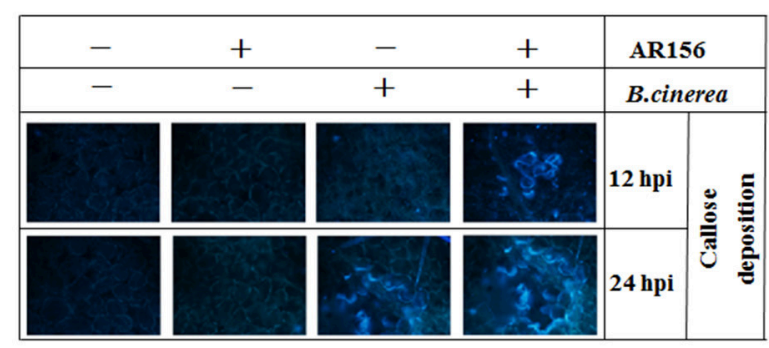

D

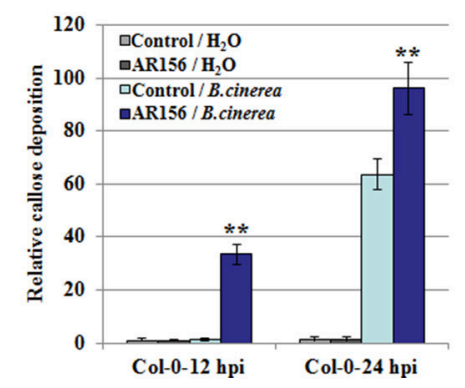

FIGURE 2 | AR156 pretreatment induces PR1 protein expression, $\mathrm{H}_{2} \mathrm{O}_{2}$ accumulation and callose deposition in systemic leaves infected with B. cinerea Arabidopsis Col-0 plants were infected by $\boldsymbol{B}$. cinerea spore suspension $\left(1 \times 10^{6}\right.$ spores $\left./ \mathrm{ml}\right)$, and the leaves were collected at $12 \mathrm{hpi}$ and 24 hpi, respectively. (A) PR1 was detected by an antibody specifically recognizes PR1; Tubulin was used as an equal loading control. (B-D) ROS accumulation (B) and callose deposition (C) were detected in plants with AR156- or control-pretreatment followed by $B$. cinerea or mock infection (Solution). ROS accumulation was detected by DAB staining; Callose deposition were observed under light and epifluorescence microscopes with a UV excitation filter. Relative callose quantities in droplet inoculated leaves of

4-week-old plants. Callose was quantified from digital microscopy photographs (D). Shown are mean areas of callose per leaf relative to total leaf area $\pm S D(n=24)$. A Student's $t$-test was used to determine significant differences between the AR156-treated sample and the control $\left({ }^{* *} P<0.01\right)$. Similar results were obtained in three independent repeats.

wild type plants. In contrast, no discernable difference could be observed between the control- and AR156-treated plants on the jar1, ein2 and npr1 mutant plants, indicating the AR156-mediated protection was jeopardized in these mutant plants (Figure 3A, AR156 set). In consistence, plants with AR156 pretreatment exhibited a significant $(P<0.01)$ reduction in necrosis size on Col-0, sid2-2 and NahG plants, but not the jar1, ein 2 and npr1 mutant plants, when compared with controltreated plants (Figure 3B). Fungal growth in each signaling mutant plants were also examined at $2 \mathrm{dpi}$. In consistence with the disease symptom observed on leaf surface, dramatically reduced fungal growth was detected in Col-0, sid2-2 and NahG plants. In contrast, this protection was abolished in jar1, ein2 and npr 1 mutant plants (Figure 3C). These results suggested that AR156-mediated ISR functions by activating the JA/ET signaling pathway and is dependent on NPR1.

It is known that plant innate immunity is modulated by phytohormone signaling networks. To investigate the signaling pathways employed by AR156-mediated ISR, we inspected the transcription of signaling pathway reporter genes, such as $P R 1$, PR2, PR5, and PDF1.2 by RT-PCR. Transcriptions of PR1, PR2, $P R 5$, and PDF1.2 were strongly induced at 48 hpi in Col-0, sid2-2 and NahG mutant plants pretreated with AR156 and inoculated with $B$. cinerea. Impressively, transcriptions of all these genes were not responsive to $B$. cinerea infection in the jar1, ein2 and npr1 mutant plants, perfectly conforming to the defective ISR mediated by AR156 (Figure 4A). Furthermore, cellular defense responses activated by AR156-mediated ISR was investigated in the above-mentioned five signaling mutant and their corresponding wild type Arabidopsis plants. $\mathrm{H}_{2} \mathrm{O}_{2}$ accumulation and callose deposition were detectable at $12 \mathrm{hpi}$ in Col-0, sid2-2 and NahG plants with AR156 pre-treatment, but not detectable (or to a much lesser degree) in jar1, ein2 and npr 1 mutant at the same time point. At $24 \mathrm{hpi}$, a combination of AR156 pretreatment and $B$. cinerea inoculation led to more $\mathrm{H}_{2} \mathrm{O}_{2}$ accumulation and callose deposition in the leaves of Col-0, sid2-2 and Nah G plants, compared with the control-pretreatment group. At the same time point, $\mathrm{H}_{2} \mathrm{O}_{2}$ accumulation and callose deposition were very weak in jar1, ein 2 and npr 1 plants in both control- and AR156-treated plants (Figures 4B-D).

\section{AR156-Induced ISR Activates PTI Components}

PAMP-triggered immunity (PTI) plays an important role for plant immunity against $B$. cinerea infection, in which activation of MAPKs is one of the earliest sign of PTI. Therefore, activation of MAPKs could be used as a good indicator for activated PTI, as well as defense responses (Eckardt, 2011; Meng and Zhang, 2013; Singh et al., 2013). To further investigate the relationship between AR156-induced ISR and PTI, antibodies specifically recognize MPK3 and MPK6 were used. In plants with control pretreatment, expression of MPK3 and MPK6 were detected 10 min after $B$. cinerea inoculation, which was then gradually decrease through 30 to $60 \mathrm{mpi}$. In contrast, in plants pretreated with AR156, we observed a sustained and gradually increased activation of MPK3 and MPK6 from 10 to 60 min after B. cinerea inoculation, which attained its maximums at $60 \mathrm{~min}$ (Figure 5A). Our results suggest that the AR156-mediated ISR is associated with an activated and enduring PTI response. MPK3 and MPK6 activation was also examined in sid2-2 and $N a h G$ mutant plants pretreated with AR156. Interestingly, sustained activation of MPK3 and MPK6 from 10 to $60 \mathrm{~min}$ was also detected in spite of the defect on SID2 


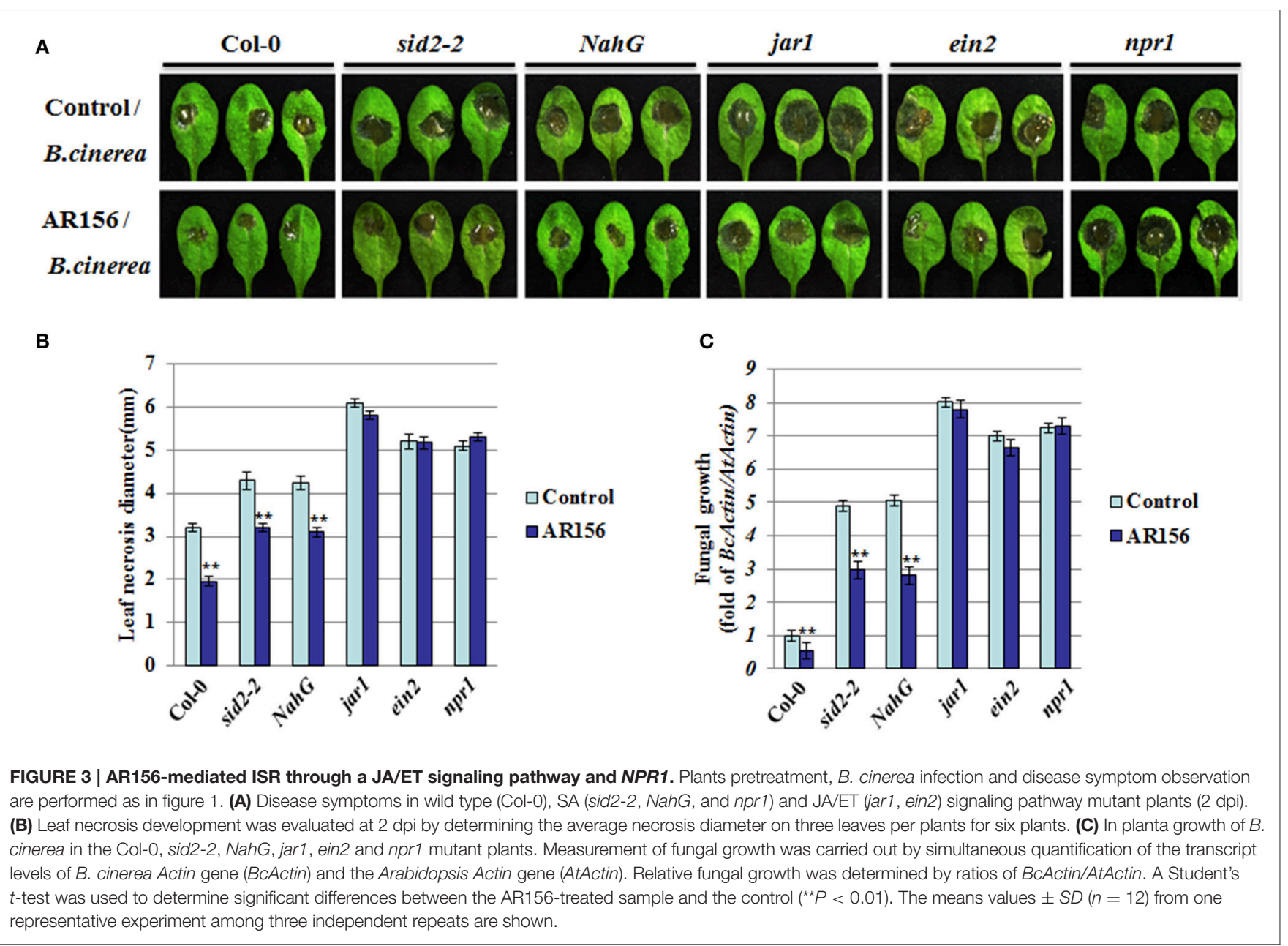

(Figure 5B) or over-expression of $\mathrm{NahG}$ (Figure 5C). Our results indicate that MPK3 and MPK6 induction is SA-dependent. This may explain why AR156-mediated ISR is SA-independent.

To further support our hypothesis, we examined other PTI marker gene, such as the flg22-induced receptor-like kinase 1 (FRK1) and WRKY53 (Asai et al., 2002; Singh et al., 2012). qRTPCR analysis showed that FRK1 and WRKY53 were activated and remained active by $B$. cinerea alone from 10 to $60 \mathrm{~min}$. However, in AR156-pretreated plants, both the expression level was significantly increased after $B$. cinerea infection, when compared to the control-pretreated plants (Figure 5D). These results confirmed that there is a close association between AR156mediated ISR and a rapid and sustained activation of PTI.

\section{DISCUSSION}

Induced systemic resistance (ISR) has been recognized as an effective biological control agent that could induce plant defense against a broad range of pathogens. Our precious studies demonstrated that B. cereus AR156 is a plant growth-promoting rhizobacterium that can induce resistance against Pst DC3000 on Arabidopsis and tomato (Niu et al., 2011, 2012). In particular, our study in Arabidopsis showed that the AR156-mediated ISR against the biotrophic pathogen Pst DC3000 is dependent on SA and NPR1, but not the ET/JA signaling pathway. In the current study, we demonstrated that the AR156-mediated ISR is also effective against the necrotrophic pathogen $B$. cinerea, and this protection is mediated by the ET/JA-, but not the SA-signaling pathway. However, we did identified NPR1 as an indispensable component of this specific ISR, despite the fact that other SA signaling pathway components were not involved. Therefore, our results indicate that the AR156-mediated ISR is effective against both bio- and necro-trophic pathogens, which make it a good candidate for broad-spectrum biological control agent. Meanwhile, our results also indicate that NPR1 could potentially function independent of the SA signaling pathway.

In recent years, many studies have associated PGPRs with improving plant health by enhancing defense against a broad range of pathogens (Pieterse et al., 2014; Rahman et al., 2014; Ma et al., 2016). B. cereus AR156 is a plant growth-promoting rhizobacterium that induces resistance against Pst DC3000 on Arabidopsis and tomato (Niu et al., 2011, 2012). The aim in this study was to explore the potential role of AR156 in eliciting ISR in Arabidopsis against B. cinerea infection. Roots application 

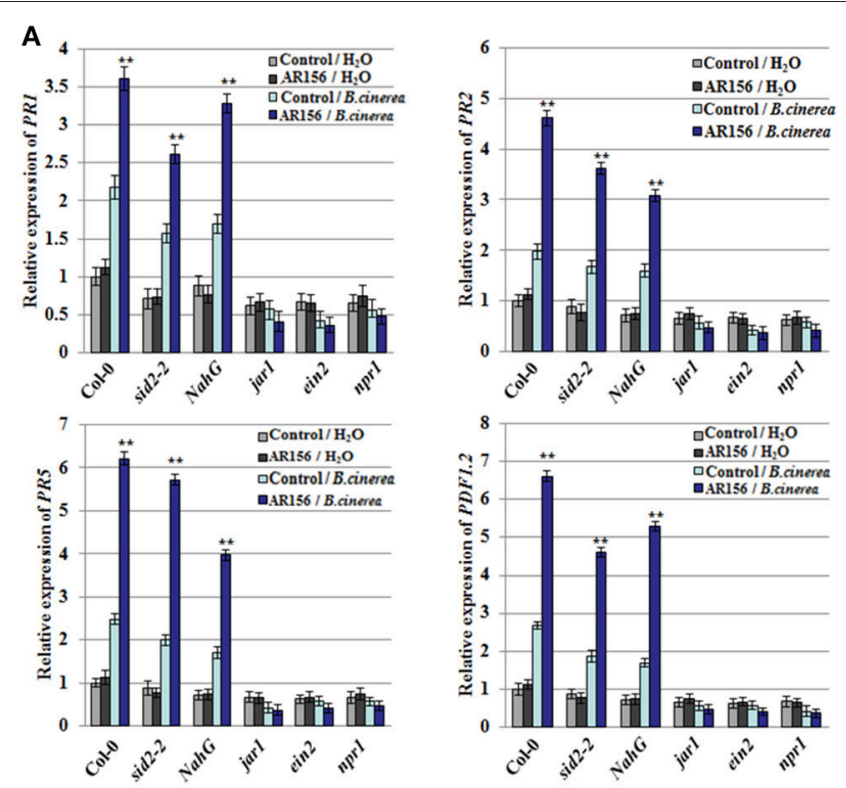

B

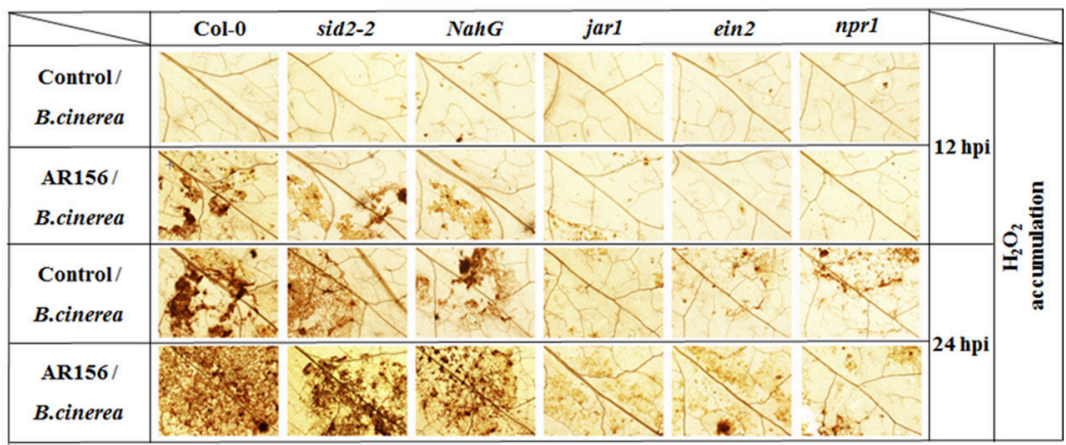

c

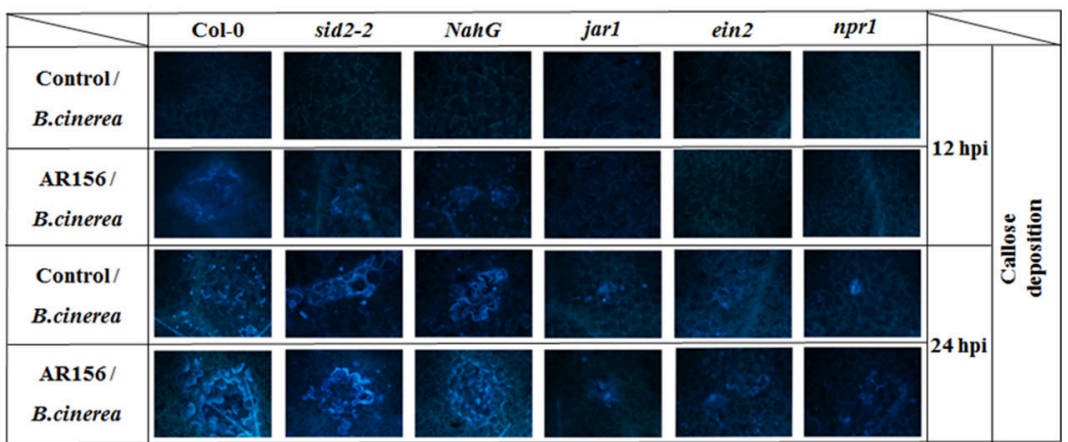

D

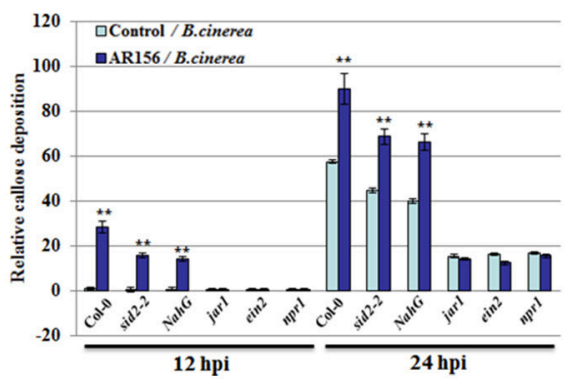

FIGURE 4 | Altered defense-related gene expression, $\mathrm{H}_{2} \mathrm{O}_{2}$ accumulation and callose deposition in Col-0, sid2-2, NahG, jar1, ein2, and npr1 mutant plants after B. cinerea infection. Four week old plants were infected with spore suspension of $B$. cinerea and leaf samples were taken 12,24 , and 48 hpi, respectively. (A) Expression of defense-related genes after $B$. cinerea infection. Expression of defense genes were analyzed by qRT-PCR and normalized with the 


\section{FIGURE 4 | Continued}

value of AtActin, which is assigned to 1. Data are presented as the means $\pm S D$ from three independent experiments and different letters above the columns represent statistically significant differences $\left(p<0.01\right.$ ) between $\mathrm{Col}-0$, sid2-2, NahG, jar1, ein2 and npr1 mutant plants. In situ detection of accumulation of $\mathrm{H}_{2} \mathrm{O}_{2}$ (B) and callose deposition (C, D) after inoculation with $B$. cinerea. Accumulation of $\mathrm{H}_{2} \mathrm{O}_{2}$ and callose deposition in leaves were detected by DAB staining and aniline blue staining, respectively. Relative callose quantities in droplet inoculated leaves of 4-week-old plants. Callose was quantified from digital microscopy photographs. Shown are mean areas of callose per leaf relative to total leaf area $\pm S D(n=24)$. A Student's $t$-test was used to determine significant differences between the AR156-treated sample and the control $\left({ }^{\star \star} P<0.01\right)$.

A

B

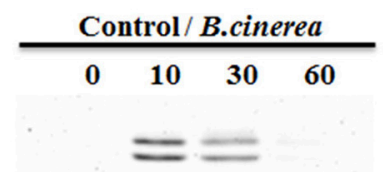

sid2-2
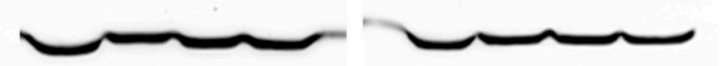

Tubulin

C

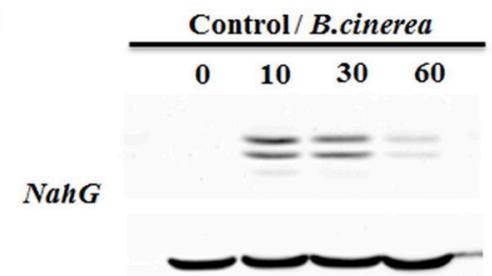

AR156/B.cinerea

$\begin{array}{lllll}0 & 10 & 30 & 60 & \min \end{array}$

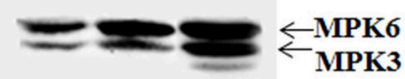

Col-0
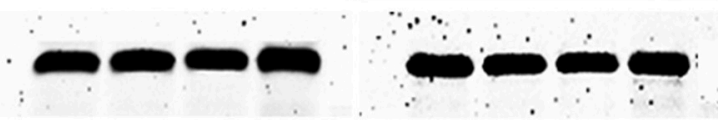

Tubulin

AR156/B.cinerea

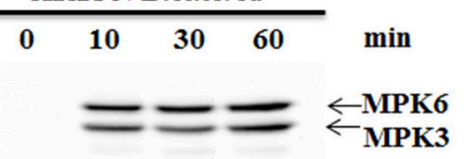

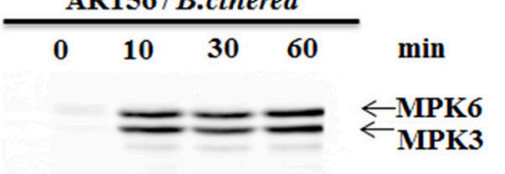

Tubulin

D
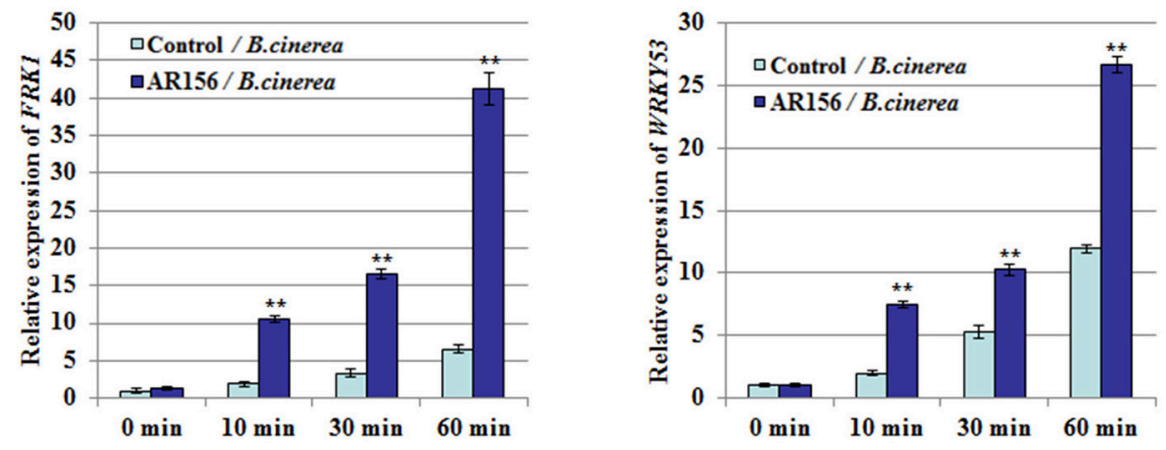

FIGURE 5 | AR156 activates PTI elements in Arabidopsis. Arabidopsis Col-0 plants are drench-applied with AR156 at $5 \times 10^{8} \mathrm{CFU} / \mathrm{ml}$ or $0.85 \% \mathrm{NaCl}(\mathrm{Control})$. The leaves were infected by B. cinerea spore suspension $\left(1 \times 10^{6} \mathrm{spores} / \mathrm{ml}\right)$. (A-C) Leaves were sampled at 0, 10, 30 and 60 min and MAPKs were detected by Western blot with an anti-Erk antibody (Cell Signaling; \#4370S). Tubulin was used as an equal loading control. (D) The transcript levels of FRK1 and WRKY53 in Arabidopsis leaves were analyzed by Real-time RT-PCR. Samples were collected at 0, 10, 30, and 60 min after inoculation with B. cinerea. AtActin mRNA was used as an internal control. The means values $\pm S D$ from three independent repeats are shown. A Student's $t$-test was used to determine significant differences between the AR156-treated sample and the control $\left({ }^{\star \star} P<0.01\right)$. 


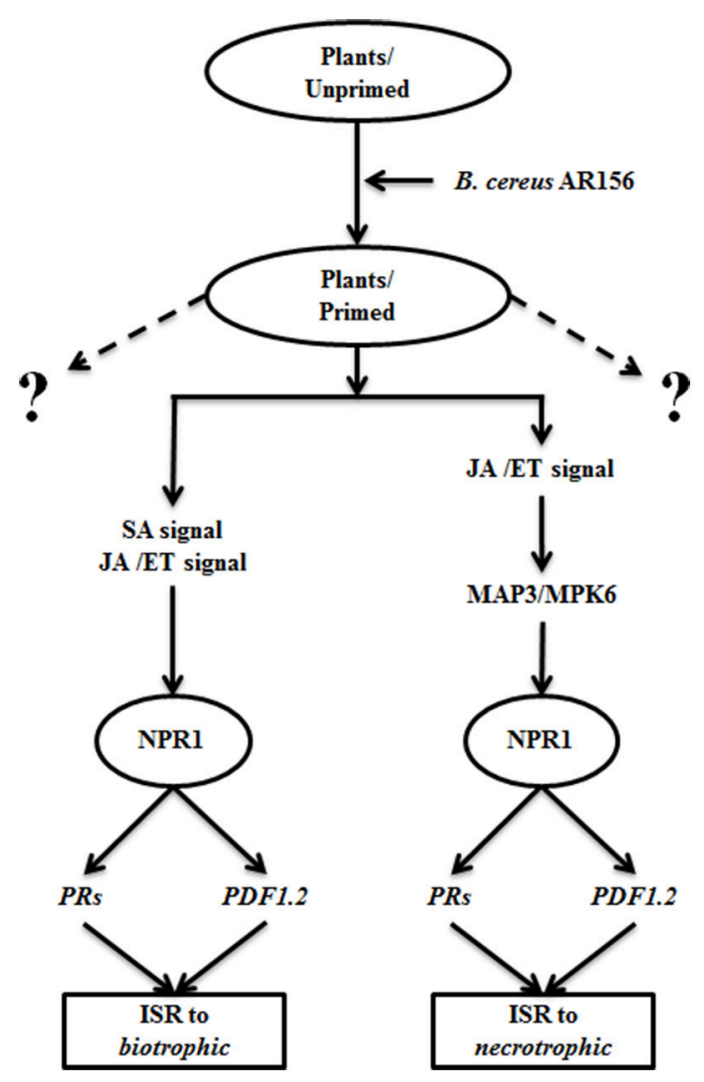

FIGURE 6 | A proposed model of AR156-mediated ISR against biotrophic and necrotrophic pathogens. When plants are pretreated with AR156, an ISR omnipotent to pathogens with both biotrophic and necrotrophic life styles is induced. When plants in a potentiated immune status is infected by a biotrophic pathogen, such as Pst DC3000, both SA and JA/ET signaling pathways are activated. Through a mechanism dependent on NPR1, downstream defense-related genes, such as PR1, PR2, PR5, and PDF1.2 are expressed, and cellular defense responses, such as $\mathrm{H}_{2} \mathrm{O}_{2}$ accumulation, callose deposition are activated; when plants are challenged with necrotrophic pathogens, such as $B$. cinerea, only the JA/ET signaling pathways is activated. The necrotrophic-effective ISR is also dependent on NPR1. Dashed lings: protective function to other unidentified elicitors.

of AR156 significantly reduced necrosis diameter and inhibited fungal growth on the leaves of Arabidopsis plants (Figure 1). Since AR156 only colonized the roots but $B$. cinerea was a foliar applied, the lack of direct contact between these two parties indicates that it is ISR, instead of a direct limitation of pathogen, leads to the observed resistance to $B$. cinerea infection.

Under primed condition, the induction of defense-related $P R$ genes following pathogen challenge has been reported in several plant-pathogen interaction (Ahn et al., 2007; Niu et al., 2011). This is also true in ISR against several hemibiotrophic and necrotrophic pathogens, such as the Harpophora oryzae-primed defense genes in the rice-Magnaporthe. oryzae interaction (Su et al., 2013) and Bacillus subtilis-induced PR genes in tomato challenged with Erwinia carotovora subsp. carotovora (Chandrasekaran and Chun, 2016). In this study, we found that PR1 protein expression was stronger in plants with AR156 pretreatment and $B$. cinerea infection than that in plants with pathogen infection only (Figure 2A). This is in consistence with reported results (Su et al., 2013; Chandrasekaran and Chun, 2016) and suggests that the induced PR expression level also contributes to defense against hemibiotrophic and necrotrophic pathogens. Rapid production of cellular defense responses in plant cells, such as quick $\mathrm{H}_{2} \mathrm{O}_{2}$ accumulation and callose deposition (Conrath et al., 2002), has been recognized as hallmark events induced by ISR-triggering bacteria (Ahn et al., 2007; Rahman et al., 2014). $\mathrm{H}_{2} \mathrm{O}_{2}$ and callose accumulation play important roles in plants response to $B$. cinerea infection (Mengiste, 2012; Schwessinger and Ronald, 2012). We found that AR156-pretreated plants accumulated higher $\mathrm{H}_{2} \mathrm{O}_{2}$ and callose levels than control-treated plants following B. cinerea infection (Figures 2B-D), suggesting that AR156 primes plants for accelerated and enhanced disease resistance capacity by activating cellular defense responses in systemic tissue.

Therefore, it interesting to seek how the defense signal is transmitted to remote tissues where the pathogen threaten has not reach yet. We investigated the involvement of SA and JA/ET signaling pathway components, which were previously demonstrated to be involved in the AR156-induced defense responses (Niu et al., 2011, 2012, 2016). AR156-induced ISR was abolished in jar1 and ein2 mutants, suggesting that the defense response is induced by AR156 through JA/ET-signaling pathways. This observation is in consistence with that the JA/ET-signaling pathways are more effective against infections by necrotrophic pathogens. Components involved in the SA signaling pathway were also examined. In our study, both sid22 and $N a h G$ plants showed comparable disease symptoms to wild type plants, and similar necrosis diameter and fungal growth in plants pretreated with AR156. SID2 is one of the genes involved in SA synthesis, defect of which leads to reduced cellular SA accumulation. NahG plants are transgenic Arabidopsis expressing an SA hydroxylase $(\mathrm{NahG})$ that degrades SA to catechol. Unaffected ISR in these two independent SA defective plants indicates that the AR156-mediated ISR against $B$. cinerea is independent of cellular SA level, and pretty much neither of the SA signaling pathway. ISR in NahG transgenic plants and defective of ISR by jar1, ein2 and npr1 have been reported in Arabidopsis previously (Pieterse et al., 1996; Ryu et al., 2003). However, there is a difference between the previous findings and ours that in their experiment, rhizobacterium treatment was not associated with induction of $P R$ gene (van Wees et al., 1999; Verhagen et al., 2004), whereas augmented PR1 protein level was observed in Arabidopsis pretreated with AR156 and then infected with $B$. cinerea (Figure 2A).

Interestingly, we previously demonstrated that in AR156mediated ISR against the biotrophic Pst DC3000, both the SAand JA/ET-signaling pathways were simultaneously activated (Niu et al., 2011). In contrast, when we analyze the AR156mediated ISR against the necrotrophic $B$. cinerea in this study, we concluded that this type of ISR was accompanied by the activation of the JA/ET-signaling pathways, but not the SA signaling pathway. It is generally accepted that biotrophic pathogens, which acquire nutrient supply from live host cells, are more vulnerable to defense through SA-signaling pathway; 
whereas necrotrophic pathogens, which benefit from host cell death, are better restrained by a JA/ET-dependent defense (Grant and Lamb, 2006). So we speculated that the favorable signal transduction pathway promoted during ISR not only depends on the ISR-inducing strains and the host plants (Pieterse et al., 2002; Choudhary and Johri, 2009; Shoresh et al., 2010), but also on the pathogens the ISR apply to.

Intriguingly, AR156-induced ISR was noticeably jeopardized in the npr 1 mutant, the gene of which encodes a redox-sensitive transcriptional regulator of SA-dependent responses. NPR1 also is a mediator of SA-JA cross talk, and a regulator of SAR and ISR (Pieterse et al., 2014). Upon activation by SA, NPR1 acts as a transcriptional coactivator of a large set of $P R$ genes as we observed in our study. This clearly laid a discrepancy between the induction of SA-dependent PRs and the independency on SA synthesis and cellular content, which may suggest a SA-unrelated function of NPR1. Indeed, NPR1 was shown to be required for the SA-independent but JA/ET-dependent ISR triggered by $P$. fluorescens WCS417r (Pieterse et al., 1998). More and more evidence point to a cytosolic function of NPR1 in JA/ET signaling and ISR (Spoel et al., 2003; Ramirez et al., 2010; Pieterse et al., 2012). It is worthy to note that NPR1 are highly expressed in Arabidopsis roots (Iyer-Pascuzzi et al., 2011), which may imply a potential role in regulating root-associated immune responses including ISR.

Our results also showed that, in AR156-primed Arabidopsis, pathogen infection triggered expression of defense-related genes, and enhanced hydrogen peroxide accumulation and callose deposition (Figure 2). However, we found that induced expression of PR1, PR2 and PR5 was also observed in sid2-2 and NahG mutants, which are defective for SA accumulation. This is a surprise to us because $P R 1, P R 2$, and $P R 5$ were generally recognized as markers of salicylic acid-dependent disease responses, which should be non-responsive in SAdeficient mutants (Vlot et al., 2009). Our results suggest that in the AR156-mediated ISR against B. cinerea, PR1, PR2 and PR5 were induced through a SA-independent signaling pathway. This is supported by a prior study in which constant $M P K 3$ and/or $M P K 6$ activation causes $P R 1$ induction independent of SA (Tsuda et al., 2013). Taken together, $P R s$ gene activation in sid2-2 and NahG by AR156 pretreatment and B. cinerea infection could be a consequence of activated JA/ET signal pathways and induced MAPKs cascade.

Previous studies already indicate the importance of MAPK signaling in plant defense against infections (Asai et al., 2002; Zipfel et al., 2004). In this study, MAPK activation was detected at $10 \mathrm{~min}$ and decreased at $60 \mathrm{~min}$ in the leaves of plants only inoculated with $B$. cinerea, but this induction initiated at about the same time but remained very strong at $60 \mathrm{~min}$ in those treated with AR156 and inoculated with $B$. cinerea (Figure 4A). This indicated that AR156-pretreatment induced stronger MAPK activation than plants without pretreatment. MPK3 and MPK6 are positive regulators of plant defense responses controlling ET (Tena et al., 2011; Meng and Zhang, 2013) and JA biosynthesis (Schweighofer and Meskiene, 2008). MPK3 and MPK6 are essential for plant defense against B. cinerea (Ren et al., 2008; Han et al., 2010; Galletti et al., 2011; Mendez-Bravo et al.,
2011). This is consistent with our finding that AR156-induced ISR against $B$. cinerea is mediated by JA/ET-signaling pathways. qRT-PCR analysis of the MAMP-specific early-defense marker genes, such as FRK1 and WRKY53 showed that MAMP-mediated defense responses occur rapidly after treatment with AR156 and inoculation with pathogen (Figure 5D), implying that AR156 induces SAR through the activation PTI response.

In our previous study, the AR156-mediated ISR could efficiently protect plants against infections by biotrophic pathogen, such as Pst DC3000. This ISR simultaneously activate the SA- and the JA/ET-dependent signaling pathways, as evident by the induced expression of PR1, PR2, PR5, and PDF1.2 (Niu et al., 2011). In this study, we demonstrated that AR156 was also effective in protecting plant from infection by necrotrophic pathogens, such as B. cinerea. However, in this case, the JA/ET signaling pathways but not the SA signaling pathway is involved. In both cases the induced ISR is associated with similar defense responses, such as activated cellular defense responses, such as $\mathrm{H}_{2} \mathrm{O}_{2}$ accumulation, callose deposition, and expression of some defense related genes. Therefore, we propose a model that AR156-mediated ISR is effective against infection by pathogens with different life cycles. In this model, when plants are pretreated with AR156, ISR is activated by equipping plants with a potentiated immune status that is omnipotent to pathogens with both biotrophic and necrotrophic life styles. When plants in potentiated status are infected by a biotrophic pathogen, such as Pst DC3000, both SA and JA/ET signaling pathways are activated. Through a mechanism dependent on NPR1, downstream defense-related genes, such as PR1, PR2, $P R 5$, and $P D F 1.2$ are expressed, and cellular defense responses, such as $\mathrm{H}_{2} \mathrm{O}_{2}$ accumulation, callose deposition are activated; when plants are challenged with necrotrophic pathogens, such as $B$. cinerea, only the JA/ET signaling pathways is activated. Once again through a NPR1-dependent mechanism, downstream defense responses are activated, leading to increase resistance (Figure 6). However, whether the role of NPR1 is conserved between the SA and JA/ET signaling pathways is unclear to us. Further study is needed to clarify the versatile function of NPR1 in AR156-mediated ISR, which is of great significance in promoting the application of AR156 in crops protection.

\section{AUTHOR CONTRIBUTIONS}

$\mathrm{DN}$ and $\mathrm{HZ}$ designed the study. PN, XL, and SW performed the experiments. All authors analyzed the data. DN and $\mathrm{HZ}$ wrote the manuscript. All authors contributed to the research and approved the final version of the manuscript.

\section{ACKNOWLEDGMENTS}

We thank Profs. Zhou J.M. (National Institute of Biological Sciences, Beijing) and Qi Y.J. (Tsinghua University, Beijing) for kindly providing us with the seeds of Arabidopsis mutants, Prof. Dong H.S. (Nanjing Agricultural University, Nanjing) for Arabidopsis transgenic line NahG, Prof. Wei L.H (Jiangsu Academy of Agricultural Sciences, Nanjing) for Botrytis cinerea 
strain B1301. This work was supported by the National Natural Science Foundation of China (31501621) to Niu N. and a Fundamental Research Funds for the Central Universities (KYTZ201403) and a PhD Programs Foundation of Ministry of Education of China (B0201300664) to HZ.

\section{REFERENCES}

Ahn, I. P., Lee, S. W., and Suh, S. C. (2007). Rhizobacteria-induced priming in Arabidopsis is dependent on ethylene, jasmonic acid, and NPR1. Mol. Plant Microbe Interact. 20, 759-768. doi: 10.1094/MPMI-207-0759

Alonso, J. M., Hirayama, T., Roman, G., Nourizadeh, S., and Ecker, J. R. (1999). EIN2, a bifunctional transducer of ethylene and stress responses in Arabidopsis. Science 284, 2148-2152. doi: 10.1126/science.284.5423.2148

Altenbach, D., and Robatzek, S. (2007). Pattern recognition receptors: from the cell surface to intracellular dynamics. Mol. Plant Microbe Interact. 20, 1031-1039. doi: 10.1094/MPMI-20-9-1031

Asai, T., Tena, G., Plotnikova, J., Willmann, M. R., Chiu, W. L., Gomez-Gomez, L., et al. (2002). MAP kinase signalling cascade in Arabidopsis innate immunity. Nature 415, 977-983. doi: 10.1038/415977a

Bowling, S. A., Guo, A., Cao, H., Gordon, A. S., Klessig, D. F., and Dong, X. I. (1994). A mutation in Arabidopsis that leads to constitutive expression of systemic acquired-resistance. Plant Cell 6, 1845-1857. doi: $10.1105 /$ tpc.6.12.1845

Chandrasekaran, M., and Chun, S. C. (2016). Expression of PR-protein genes and induction of defense-related enzymes by Bacillus subtilis CBR05 in tomato (Solanum lycopersicum) plants challenged with Erwinia carotovora subsp. carotovora. Biosci. Biotechnol. Biochem. 80, 2277-2283. doi: $10.1080 / 09168451.2016 .1206811$

Chisholm, S. T., Coaker, G., Day, B., and Staskawicz, B. J. (2006). Host-microbe interactions: shaping the evolution of the plant immune response. Cell 124, 803-814. doi: 10.1016/j.cell.2006.02.008

Choudhary, D. K., and Johri, B. N. (2009). Interactions of Bacillus spp. and plants With special reference to induced systemic resistance (ISR). Microbiol. Res. 164, 493-513. doi: 10.1016/j.micres.2008.08.007

Conrath, U., Beckers, G. J. M., Flors, V., García-Agustín, P., Jakab, G., Mauch, F., et al. (2006). Priming: Getting Ready for Battle. Mol. Plant Microbe Interact. 19, 1062-1071. doi: 10.1094/MPMI-19-1062

Conrath, U., Pieterse, C. M., and Mauch-Mani, B. (2002). Priming in plant-pathogen interactions. Trends Plant Sci. 7, 210-216. doi: 10.1016/S1360-1385(02)02244-6

Conrath, U., Thulke, O., Katz, V., Schwindling, S., and Kohler, A. (2001). Priming as a mechanism in induced systemic resistance of plants. Eur. J. Plant Pathol. 107, 113-119. doi: 10.1023/A:1008768516313

Delaney, T. P. (1994). A central role of salicylic-acid in plant-disease resistance. Science 266, 1793-1793. doi: 10.1126/science.266.5188.1247

Eckardt, N. A. (2011). BIK1 function in plant growth and defense signaling. Plant Cell 23, 2806-2806. doi: 10.1105/tpc.111.230811

Fu, Z. Q., and Dong, X. (2013). Systemic acquired resistance: turning local infection into global defense. Annu. Rev. Plant Biol. 64, 839-863. doi: 10.1146/annurev-arplant-042811-105606

Galletti, R., Ferrari, S., and De Lorenzo, G. (2011). Arabidopsis MPK3 and MPK6 play different roles in basal and oligogalacturonide- or flagellininduced resistance against Botrytis cinerea. Plant Physiol. 157, 804-814. doi: 10.1104/pp.111.174003

Glazebrook, J. (2001). Genes controlling expression of defense responses in Arabidopsis - 2001 status. Curr. Opin. Plant Biol. 4, 301-308. doi: 10.1016/S1369-5266(00)00177-1

Grant, M., and Lamb, C. (2006). Systemic immunity. Curr. Opin. Plant Biol. 9, 414-420. doi: 10.1016/j.pbi.2006.05.013

Han, L., Li, G. J., Yang, K. Y., Mao, G. H., Wang, R. Q., Liu, Y. D., et al. (2010). Mitogen-activated protein kinase 3 and 6 regulate Botrytis cinereainduced ethylene production in Arabidopsis. Plant Journal 64, 114-127. doi: $10.1111 /$ j.1365-313x.2010.04318.x

\section{SUPPLEMENTARY MATERIAL}

The Supplementary Material for this article can be found online at: http://journal.frontiersin.org/article/10.3389/fpls.2017. 00238/full\#supplementary-material

Heil, M., and Bostock, R. M. (2002). Induced systemic resistance (ISR) against pathogens in the context of induced plant defences. Ann. Bot. 89, 503-512. doi: $10.1093 / \mathrm{aob} / \mathrm{mcf076}$

Iyer-Pascuzzi, A. S., Jackson, T., Cui, H. C., Petricka, J. J., Busch, W., Tsukagoshi, H., et al. (2011). Cell identity regulators link development and stress responses in the Arabidopsis root. Dev. Cell 21, 770-782. doi: 10.1016/j.devcel.2011.09.009

Jones, J. D., and Dangl, J. L. (2006). The plant immune system. Nature 444, 323-329. doi: 10.1038/nature05286

Luna, E., Pastor, V., Robert, J., Flors, V., Mauch-Mani, B., and Ton, J. (2011). Callose deposition: a multifaceted plant defense response. Mol. Plant Microbe Interact. 24, 183-193. doi: 10.1094/MPMI-07-10-0149

Ma, Z., Hua, G. K., Ongena, M., and Hofte, M. (2016). Role of phenazines and cyclic lipopeptides produced by pseudomonas sp. CMR12a in induced systemic resistance on rice and bean. Environ. Microbiol. Rep. 8, 896-904. doi: 10.1111/1758-2229.12454

Mendez-Bravo, A., Calderon-Vazquez, C., Ibarra-Laclette, E., Raya-Gonzalez, J., Ramirez-Chavez, E., Molina-Torres, J., et al. (2011). Alkamides activate jasmonic acid biosynthesis and signaling pathways and confer resistance to Botrytis cinerea in Arabidopsis thaliana. PLoS ONE 6:e27251 doi: 10.1371/journal.pone.0027251

Meng, X., and Zhang, S. (2013). MAPK cascades in plant disease resistance signaling. Annu. Rev. Phytopathol. 51, 245-266. doi: 10.1146/annurev-phyto-082712-102314

Mengiste, T. (2012). Plant immunity to necrotrophs. Annu. Rev. Phytopathol. 50, 267-294. doi: 10.1146/annurev-phyto-081211-172955

Niu, D. D., Liu, H. X., Jiang, C. H., Wang, Y. P., Wang, Q. Y., Jin, H. L., et al. (2011). The plant growth-promoting rhizobacterium Bacillus cereus AR156 induces systemic resistance in Arabidopsis thaliana by simultaneously activating salicylate- and jasmonate/ethylene-dependent signaling pathways. Mol. Plant Microbe Interact. 24, 533-542. doi: 10.1094/MPMI-09-10-0213

Niu, D. D., Wang, C. J., Guo, Y. H., Jiang, C. H., Zhang, W. Z., Wang, Y. P., et al. (2012). The plant growth-promoting rhizobacterium Bacillus cereus AR156 induces resistance in tomato with induction and priming of defence response. Biocontrol Sci. Technol. 22, 991-1004. doi: 10.1080/09583157.2012.706595

Niu, D. D., Wang, X. J., Wang, Y. R., Song, X. O., Wang, J. S., Guo, J. H., et al. (2016). Bacillus cereus AR156 activates PAMP-triggered immunity and induces a systemic acquired resistance through a NPR1- and SAdependent signaling pathway. Biochem. Biophys. Res. Commun. 469, 120-125. doi: 10.1016/j.bbrc.2015.11.081

Pastor, V., Luna, E., Ton, J., Cerezo, M., Garcia-Agustin, P., and Flors, V. (2013). Fine tuning of reactive oxygen species homeostasis regulates primed immune responses in Arabidopsis. Mol. Plant Microbe Interact. 26, 1334-1344. doi: 10.1094/MPMI-04-13-0117-R

Pieterse, C. M., vanWees, S. C., Hoffland, E., vanPelt, J. A., and vanLoon, L. C. (1996). Systemic resistance in Arabidopsis induced by biocontrol bacteria is independent of salicylic acid accumulation and pathogenesis-related gene expression. Plant Cell 8, 1225-1237. doi: 10.1105/tpc.8.8.1225

Pieterse, C. M., Van der Does, D., Zamioudis, C., Leon-Reyes, A., and Van Wees, S. C. M. (2012). Hormonal modulation of plant immunity. Annu. Rev. Cell Dev. Biol. 28, 489-521. doi: 10.1146/annurev-cellbio-092910-154055

Pieterse, C. M. J., Van Wees, S. C. M., Ton, J., Van Pelt, J. A., and Van Loon, L. C. (2002). Signalling in rhizobacteria-induced systemic resistance in Arabidopsis thaliana. Plant Biol. 4, 535-544. doi: 10.1055/s-2002-35441

Pieterse, C. M., van Wees, S. C., van Pelt, J. A., Knoester, M., Laan, R., Gerrits, H., et al. (1998). A novel signaling pathway controlling induced systemic resistance in Arabidopsis. Plant Cell 10, 1571-1580. doi: 10.1105/tpc.10.9.1571

Pieterse, C. M., Zamioudis, C., Berendsen, R. L., Weller, D. M., Van Wees, S. C., and Bakker, P. A. (2014). Induced systemic resistance by beneficial microbes. Annu. Rev. Phytopathol. 52, 347-375. doi: 10.1146/annurev-phyto-082712-102340 
Rahman, A., Uddin, W., and Wenner, N. G. (2014). Induced systemic resistance responses in perennial ryegrass against Magnaporthe oryzae elicited by semipurified surfactin lipopeptides and live cells of Bacillus amyloliquefaciens. Mol. Plant Pathol. 16, 546-558. doi: 10.1111/mpp.12209

Ramirez, V., Van der Ent, S., Garcia-Andrade, J., Coego, A., Pieterse, C. M., and Vera, P. (2010). OCP3 is an important modulator of NPR1-mediated jasmonic acid-dependent induced defenses in Arabidopsis. BMC Plant Biol. 10:199. doi: 10.1186/1471-2229-10-199

Ren, D., Liu, Y., Yang, K., Han, L., Mao, G., Glazebrook, J., et al. (2008). A fungalresponsive MAPK cascade regulates phytoalexin biosynthesis in Arabidopsis. Proc. Natl. Acad. Sci. U.S.A. 105, 5638-5643. doi: 10.1073/pnas.0711301105

Ryu, C. M., Hu, C. H., Reddy, M. S., and Kloepper, J. W. (2003). Different signaling pathways of induced resistance by rhizobacteria in Arabidopsis thaliana against two pathovars of Pseudomonas syringae. New Phytol. 160, 413-420. doi: 10.1046/j.1469-8137.2003.00883.x

Salas-Marina, M. A., Silva-Flores, M. A., Uresti-Rivera, E. E., Castro-Longoria, E., Herrera-Estrella, A., and Casas-Flores, S. (2011). Colonization of Arabidopsis roots by Trichoderma atroviride promotes growth and enhances systemic disease resistance through jasmonic acid/ethylene and salicylic acid pathways. Eur. J. Plant Pathol. 131, 15-26. doi: 10.1007/s10658-0119782-6

Schweighofer, A., and Meskiene, I. (2008). Regulation of stress hormones jasmonates and ethylene by MAPK pathways in plants. Mol. Biosyst. 4, 799-803. doi: $10.1039 / \mathrm{b} 718578 \mathrm{~m}$

Schwessinger, B., and Ronald, P. C. (2012). Plant innate immunity: perception of conserved microbial signatures. Annu. Rev. Plant Biol. 63, 451-482. doi: 10.1146/annurev-arplant-042811-105518

Schwessinger, B., and Zipfel, C. (2008). News from the frontline: recent insights into PAMP-triggered immunity in plants. Curr. Opin. Plant Biol. 11, 389-395. doi: $10.1016 /$ j.pbi.2008.06.001

Shoresh, M., Harman, G. E., and Mastouri, F. (2010). Induced systemic resistance and plant responses to fungal biocontrol agents. Annu. Rev. Phytopathol. 48, 21-43. doi: 10.1146/annurev-phyto-073009-114450

Singh, P., Chien, C. C., Mishra, S., Tsai, C. H., and Zimmerli, L. (2013). The Arabidopsis LECTIN RECEPTOR KINASE-VI.2 is a functional protein kinase and is dispensable for basal resistance to Botrytis cinerea. Plant Signal. Behav. 8:e22611. doi: 10.4161/psb.22611

Singh, P., Kuo, Y. C., Mishra, S., Tsai, C. H., Chien, C. C., Chen, C. W., et al. (2012). The lectin receptor kinase-VI.2 is required for priming and positively regulates Arabidopsis pattern-triggered immunity. Plant Cell 24, 1256-1270. doi: $10.1105 /$ tpc.112.095778

Speth, E. B., Lee, Y. N., and He, S. Y. (2007). Pathogen virulence factors as molecular probes of basic plant cellular functions. Curr. Opin. Plant Biol. 10, 580-586. doi: 10.1016/j.pbi.2007.08.003

Spoel, S. H., Koornneef, A., Claessens, S. M., Korzelius, J. P., Van Pelt, J. A., Mueller, M. J., et al. (2003). NPR1 modulates cross-talk between salicylateand jasmonate-dependent defense pathways through a novel function in the cytosol. Plant Cell 15, 760-770. doi: 10.1105/tpc.009159

Staswick, P. E., Su, W., and Howell, S. H. (1992). Methyl jasmonate inhibition of root-growth and induction of a leaf protein are decreased in an Arabidopsis-Thaliana mutant. Proc. Natl. Acad. Sci. U.S.A. 89, 6837-6840. doi: 10.1073/pnas.89.15.6837

Su, Z. Z., Mao, L. J., Li, N., Feng, X. X., Yuan, Z. L., Wang, L. W., et al. (2013). Evidence for biotrophic lifestyle and biocontrol potential of dark septate endophyte Harpophora oryzae to rice blast disease. PLoS ONE 8:e61332. doi: 10.1371/journal.pone.0061332

Tena, G., Boudsocq, M., and Sheen, J. (2011). Protein kinase signaling networks in plant innate immunity. Curr. Opin. Plant Biol. 14, 519-529. doi: 10.1016/j.pbi.2011.05.006

Tsuda, K., Mine, A., Bethke, G., Igarashi, D., Botanga, C. J., Tsuda, Y., et al. (2013). Dual regulation of gene expression mediated by extended MAPK activation and salicylic acid contributes to robust innate immunity in Arabidopsis thaliana. PLoS Genet. 9:e1004015. doi: 10.1371/journal.pgen. 1004015

Van der Ent, S., Verhagen, B. W., Van Doorn, R., Bakker, D., Verlaan, M. G., Pel, M. J., et al. (2008). MYB72 is required in early signaling steps of rhizobacteriainduced systemic resistance in Arabidopsis. Plant Physiol. 146, 1293-1304. doi: 10.1104/pp.107.113829

van Loon, L. C., Bakker, P. A., and Pieterse, C. M. J. (1998). Systemic resistance induced by rhizosphere bacteria. Annu. Rev. Phytopathol. 36, 453-483. doi: 10.1146/annurev.phyto.36.1.453

Van Oosten, V. R., Bodenhausen, N., Reymond, P., Van Pelt, J. A., Van Loon, L. C., Dicke, M., et al. (2008). Differential effectiveness of microbially induced resistance against herbivorous insects in Arabidopsis. Mol. Plant Microbe Interact. 21, 919-930. doi: 10.1094/MPMI-217-0919

van Wees, S. C., Luijendijk, M., Smoorenburg, I., van Loon, L. C., and Pieterse, C. M. (1999). Rhizobacteria-mediated induced systemic resistance (ISR) in Arabidopsis is not associated with a direct effect on expression of known defense-related genes but stimulates the expression of the jasmonate-inducible gene Atvsp upon challenge. Plant Mol. Biol. 41, 537-549. doi: 10.1023/A:1006319216982

Verhagen, B. W., Glazebrook, J., Zhu, T., Chang, H. S., van Loon, L. C., and Pieterse, C. M. J. (2004). The transcriptome of rhizobacteria-induced systemic resistance in Arabidopsis. Mol. Plant Microbe Interact. 17, 895-908. doi: 10.1094/MPMI.2004.17.8.895

Vlot, A. C., Dempsey, D. A., and Klessig, D. F. (2009). Salicylic acid, a multifaceted hormone to combat disease. Annu. Rev. Phytopathol. 47, 177-206. doi: 10.1146/annurev.phyto.050908.135202

Yedidia, I., Shoresh, M., Kerem, Z., Benhamou, N., Kapulnik, Y., and Chet, I. (2003). Concomitant induction of systemic resistance to Pseudomonas syringae pv. lachrymans in cucumber by Trichoderma asperellum (T-203) and accumulation of phytoalexins. Applied Environ. Microbiol. 69, 7343-7353. doi: 10.1128/AEM.69.12.7343-7353.2003

Zipfel, C., Robatzek, S., Navarro, L., Oakeley, E. J., Jones, J. D. G., Felix, G., et al. (2004). Bacterial disease resistance in Arabidopsis through flagellin perception. Nature 428, 764-767. doi: 10.1038/nature02485

Conflict of Interest Statement: The authors declare that the research was conducted in the absence of any commercial or financial relationships that could be construed as a potential conflict of interest.

Copyright (c) 2017 Nie, Li, Wang, Guo, Zhao and Niu. This is an open-access article distributed under the terms of the Creative Commons Attribution License (CC BY). The use, distribution or reproduction in other forums is permitted, provided the original author(s) or licensor are credited and that the original publication in this journal is cited, in accordance with accepted academic practice. No use, distribution or reproduction is permitted which does not comply with these terms. 